\title{
Midterm Report on Removal of Radioactive Iodine and Cesium from Rainwater Contaminated by Fukushima Daiichi Nuclear Accident
}

\author{
Water Analysis Group \\ The Ad Hoc Committee on Safety Measures against Radio-active \\ Iodine and Cesium of the Japanese Society of Radiation Safety Management
}

The removal rate of radioactive materials from contaminated water was experimentally obtained using various materials and commercial water purifiers with the aim of enabling the public to easily remove radioactive materials from rainwater and tap water contaminated by radioactive ${ }^{131} \mathrm{I},{ }^{134} \mathrm{Cs}$, and ${ }^{137} \mathrm{Cs}$ released by the Fukushima Daiichi Nuclear Power Plant accident using readily obtainable instruments and materials at home. Since it was difficult to obtain contaminated tap water, contaminated rainwater was used as samples in our experiments. In the rainwater, ${ }^{131} \mathrm{I},{ }^{132} \mathrm{I},{ }^{134} \mathrm{Cs},{ }^{137} \mathrm{Cs},{ }^{132} \mathrm{Te},{ }^{129 \mathrm{~m}} \mathrm{Te}$, and ${ }^{129} \mathrm{Te}$ were detected. The abundance ratio of the isotopes depended on the location and date of collection, and the abundance of ${ }^{131} \mathrm{I}$ was 12 to 26 times higher than that of ${ }^{137} \mathrm{Cs}$. Most of the radioactivity in the rainwater originated from ${ }^{131} \mathrm{I}$. The removal rate was obtained in the case of using readily available materials and water purifiers at home and in a university laboratory. The results of model experiments using nonradioactive $I_{3}{ }^{\circ}$ and radioactive ${ }^{125} I$ instead of ${ }^{131} I$ suggested that activated carbon was effective. On the basis of these results, we investigated the removal rates of radioactive iodine and cesium using five different pot-type water purifiers with activated carbon as the basic adsorbent, to which ion-exchange resin, a hollow fiber membrane, or a ceramic was added. Approximately 90 to $99 \%$ of ${ }^{131}$ I and 94 to $100 \%$ of ${ }^{137} \mathrm{Cs}$ were removed by consecutive purifications using the pot-type water purifiers. These results indicated that these water purifiers can be easily used to remove ${ }^{131} \mathrm{I}$ and ${ }^{137} \mathrm{Cs}$ at home, although special care is required when boiling using an electric kettle because it causes the concentration of ${ }^{131}$ I. Faucet-mounted- and countertop-type water purifiers with activated carbon as the basic material are expected to have a similar performance to pot-type water purifiers, although this requires future experimental verification. We found that $1-9 \%$ of the radioactive ${ }^{131} I$ remained in the rainwater samples after repeated treatment with the pot-type commercial water purifiers, depending on the sampling location and time, and that some of the residual isotopes were adsorbed on silica nanoparticles. Furthermore, to improve the removal rate, it is necessary to develop a removal method for the remaining components.

Key words: removal, rainwater, radioactive iodine, radioactive cesium, pot-type water purifier

\section{Introduction}

The Ad Hoc Committee on Safety Measures against Radioactive Iodine and Cesium of the Japanese Society of Radiation Safety Management established a water analysis group composed of members from four universities and one organization, each of which conducted various experiments until $29^{\text {th }}$ April 2011. The aim of the water analysis group is to discuss removal methods and propose decontamination methods for radioactive materials from tap water and rainwater con- taminated by the release of radioactive iodine and cesium from the Fukushima Daiichi Nuclear Power Plant. With the aim of developing a removal method for radioactive materials using easily obtainable materials and water purifiers that can be found in a general home, the removal rate of various isotopes was obtained by performing model experiments and experiments on contaminated samples in a university laboratory. Since contaminated tap water was difficult to obtain, contaminated rainwater was used in this study. The results were immediately published
Corresponding author: Hirokazu Miyoshi

Radioisotope Research Center, the University of Tokushima

3-18-15 Kuromoto-cho, Tokushima 770-8503, Japan
TEL: 088-633-9984

FAX: 088-633-9417

E-mail:hmiyoshi@ri.tokushima-u.ac.jp 
Table 1 Removal rate of nonradioactive $\mathrm{I}_{3}^{-}$from aqueous solution using commercial water purifier.

\begin{tabular}{ccccc}
\hline Pot-type water Purifiers & Filter Materials & Location of Experiment & Sample & $\mathrm{R}(\%)$ of $\mathrm{I}_{2}+\mathrm{I}^{-}$ \\
\hline Brita Navelia & Activated Carbon + Ion Exchange Resin & TKS & $0.1 \mathrm{mM} \mathrm{I}_{3}^{\circ}$ aq. & 98 \\
\hline
\end{tabular}

online in Japanese, and this report is an English translation of the study.

The main methods, results, and consideration are simply listed in point form in this report. Some details are omitted in this report, which will be given in our final report.

\section{Methods, Results, and Consideration}

Five different pot-type commercial water purifiers, which contained activated carbon in addition to ion exchange resin, a hollow fiber filter, or a ceramic, were used to determine the rates of ${ }^{131} \mathrm{I},{ }^{134} \mathrm{Cs}$, and ${ }^{137} \mathrm{Cs}$ removal from contaminated rainwater. In a preliminary experiment, a nonradioactive iodine solution $(0.1 \mathrm{mM})$ and a radioactive ${ }^{125} \mathrm{I}$ solution $(4.9 \mathrm{MBq} / \mathrm{L}$, Bolton-Hunter, KI disposable mixing solution) were used to model ${ }^{131}$ I. $\beta$-Cyclodextrin paper (CDP), pretreated activated carbon, soft-wheat flour, potato starch, tororo (very thin shavings of seaweed), silver ions, silver nanoparticles (NPs), a silver plate, ion exchange resin (mixed resin), silica NPs, and a kettle for boiling were used to remove ${ }^{131} \mathrm{I}$ from rainwater. Ultrafiltration was also carried out. Membrane filters having pores of $1.2 \mu \mathrm{m}, 0.45 \mu \mathrm{m}$, and $0.2 \mu \mathrm{m}$ size were purchased from Sartorius Co., Ltd. Ultrafiltration filters (Amicon YM-10 (MWCO 100,000) and YM-1 (MWCO 1,000)) having pores of $10 \mathrm{~nm}$ and $2.6 \mathrm{~nm}$ size, respectively, were purchased from Millipore Co., Ltd. Radionuclide analysis and measurement of the radioactivity of the radioactive materials were performed using a Ge semiconductor detector and a $\gamma$-counter, respectively, at each university and organization participating in this study.

In this study, the removal rate is defined as

$$
R(\%)=\frac{A_{0}-A}{A_{0}} \times 100,
$$

where $R(\%)$ is the removal rate, $A_{0}$ is the radioactivity concentration before treatment $(\mathrm{Bq} / \mathrm{L})$, and $A$ is the radioactivity concentration after treatment $(\mathrm{Bq} / \mathrm{L})$. Here, the treatment refers to the method used to remove radioactive iodide and cesium, and the abbreviations TKS, S, T, and KEK denote Tokushima, Shizuoka, and Tokyo Universities and the High Energy Accelerator Research Organization, respectively.

\section{[1] Model experiments (TKS)}

1. Effectiveness of removing nonradioactive $\mathrm{I}_{3}{ }^{-}$from aqueous solution using commercial water purifier

(Method)

A $0.1 \mathrm{mM} \mathrm{I}_{3}$ aqueous solution was prepared by the 100 -fold dilution of a nonradioactive solution with distilled water for use as a sample solution in the first model experiment. The removal rate was calculated from the UV-vis absorption spectra before and after the filtration of the sample using the water purifier.

(Result)

$\mathrm{I}_{3}^{-}$aqueous solution $\left(\mathrm{I}_{2}\right.$ and $\left.\mathrm{I}\right)$ could be purified using a pottype commercial water purifier containing activated carbon and ion exchange resin with an $\mathrm{I}_{3}^{-}$removal rate of $98 \%$ (average value of five measurements), as shown in Table 1.

\section{(Consideration)}

The observed removal rate of $98 \%$ for nonradioactive iodine suggested that it is possible to remove even radioactive iodine using a commercial water purifier containing activated carbon with high efficiency.

\section{Effectiveness of various materials for removing ${ }^{125}$ I from ${ }^{125}$ I aqueous solution}

(Method)

The removal rates of ${ }^{125} \mathrm{I}$ for six different materials placed in a filter paper used to make filter coffee at home were obtained by measuring the radioactivity of a filtrated ${ }^{125} \mathrm{I}(4.9 \mathrm{MBq} / \mathrm{L}$, Bolton-Hunter, KI disposable mixing solution) model solution.

Table 2 Rates of ${ }^{125}$ | removal from ${ }^{125}$ I aqueous solution using various materials.

\begin{tabular}{lc}
\hline \multicolumn{1}{c}{ Filter Materials: Weight $(\mathrm{g})$} & $\mathrm{R}(\%)$ of ${ }^{125} \mathrm{I}$ \\
\hline Paper Filter (PF): 1.26 & 14 \\
\hline PF+Activated Carbon: 16.79 & 39 \\
\hline FP+Pretreated Activated Carbon & 85 \\
\hline PF+Soft-Wheat Flour: 3.45 & 30 \\
\hline PF+Tororo: 37.04 & 23 \\
\hline PF+Potato Starch: 30.04 & 25 \\
\hline PF+ $\beta$-CDP: 17.83 & 72 \\
\hline
\end{tabular}


Table 3 Radioactivity concentrations and ratios of radioactivity for water samples collected at various times, dates, and locations.

\begin{tabular}{|c|c|c|c|c|c|c|c|}
\hline \multirow[t]{2}{*}{ Location of Collection } & \multirow[t]{2}{*}{ Type of Water } & \multirow{2}{*}{ Sampling Date and Time } & \multicolumn{3}{|c|}{$\begin{array}{l}\text { Radioactivity Concentration } \\
\text { at Sampling Time }(\mathrm{Bq} / \mathrm{L})\end{array}$} & \multicolumn{2}{|c|}{ Ratios of Radioactivity } \\
\hline & & & ${ }^{131}$ I & ${ }^{134} \mathrm{Cs}$ & ${ }^{137} \mathrm{Cs}$ & ${ }^{131} \mathrm{I} /{ }^{137} \mathrm{Cs}$ & ${ }^{134} \mathrm{Cs} /{ }^{137} \mathrm{Cs}$ \\
\hline Hitachi City & Rainwater & 16:40, 21st March, 2011 & 3458.9 & 116.8 & 133.4 & 25.9 & 0.9 \\
\hline Tokyo Metropolitan Area & Rainwater ${ }^{1)}$ & 17:00, 22nd March, 2011 & 3542.9 & 208.5 & 219.5 & 16.1 & 0.95 \\
\hline Tsukuba City & Rainwater & 0:00, 24th, March, 2011 & 905 & - & - & - & - \\
\hline Hitachi City & Rainwater & 0:00, 24th March, 2011 & 6980 & - & - & - & - \\
\hline Hitachi City & Water Purification Plant & 9:00, 27th March, 2011 & 19.8 & 1.3 & 0.8 & 24.8 & 1.6 \\
\hline Fukushima City, Sasakino & Rainwater $^{2)}$ & -, 1st April, 2011 & 3830 & - & 236 & 16.2 & - \\
\hline Fukushima Prefecture & Rainwater & 10:00, 12th April, 2011 & 1462.2 & 109 & 127 & 11.5 & 0.9 \\
\hline
\end{tabular}

1) Filtered using qualitative analysis filter paper

2) Diluted with contaminated rainwater (15th March) sampled at Machiura Aza, Sasakino, Fukushima city

(Results)

The removal rate of ${ }^{125} \mathrm{I}$ obtained using $\beta$-CDP had a relatively high value of $72 \%$. The removal rates using activated carbon prepared from coconut shell, tororo, potato starch, and soft-wheat flour were distributed in the range of $14 \%$ to $39 \%$. However, the removal rate of ${ }^{125} \mathrm{I}$ for activated carbon prepared from coconut shell increased to $85 \%$ when the activated carbon was pretreated by washing with cold water and immersion in hot water.

\section{(Consideration)}

In the model experiments using ${ }^{125}$ I solution, although the removal rates varied among the materials, each material exhibited a constant removal rate. However, with the exception of the pretreated activated carbon prepared from coconut shell and $\beta$-CDP, a high removal rate was not obtained. The effectiveness of the activated carbon was markedly improved by the pretreatment.

\section{[2] Experiments using contaminated rainwater}

1. Radioactivity concentration and radioactivity ratio of rainwater

1.1. Table of water samples collected at various times, dates, and locations

(Method)

Table 3 shows the radioactivity concentrations and ratios of radioactivity for water samples collected at various times, dates, and locations. In the table, a dash means that no radioactivity was measured. The radioactivity concentrations and ratios of radioactivities at the sampling time are discussed in the next section.
(Results)

The sample water was collected between March 21st and April 12th, and all the samples consisted of rainwater except for one sample obtained from Hitachi water purification plant.

\subsection{Nuclide analysis}

(Method)

The nuclides were analyzed using a Ge semiconductor detector.

(Results)

Figure 1 shows a typical $\gamma$-ray spectrum of a sample of rainwater, in which peaks corresponding to ${ }^{131} \mathrm{I},{ }^{132} \mathrm{I},{ }^{134} \mathrm{Cs},{ }^{137} \mathrm{Cs}$, ${ }^{129 \mathrm{~m}} \mathrm{Te},{ }^{129} \mathrm{Te}$, and ${ }^{132} \mathrm{Te}$ can be observed.

As shown in Table 3, the radioactivity concentrations at the sampling times ranged from 20 to $7000 \mathrm{~Bq} / \mathrm{L}$ for ${ }^{131} \mathrm{I}$, 1.3 to $117 \mathrm{~Bq} / \mathrm{L}$ for ${ }^{134} \mathrm{Cs}$, and 0.8 to $236 \mathrm{~Bq} / \mathrm{L}$ for ${ }^{137} \mathrm{Cs}$, and those of ${ }^{131} \mathrm{I}$ did not decay in the following days in spite of the short half-life of ${ }^{131} \mathrm{I}$ of 8 days. There was a large variation in the radioactivity concentration with the location and time of collection. As shown in Table 3, the ratio of radioactivity was 12-26 for ${ }^{131} \mathrm{I} /{ }^{137} \mathrm{Cs}$ and $1-1.6$ for ${ }^{134} \mathrm{Cs} /{ }^{137} \mathrm{Cs}$. The radioactivity ratio of ${ }^{131} \mathrm{I} /{ }^{137} \mathrm{Cs}$ depended on the location of collection and had a twofold range.

(Consideration)

The cause of the large variation of the concentration of radioactive ${ }^{131} \mathrm{I}$ with the location and time of collection cannot be clarified because a comparative analysis between weather conditions and the amount of released ${ }^{131}$ I over time was not performed; further analysis is required. Since the ratio between 


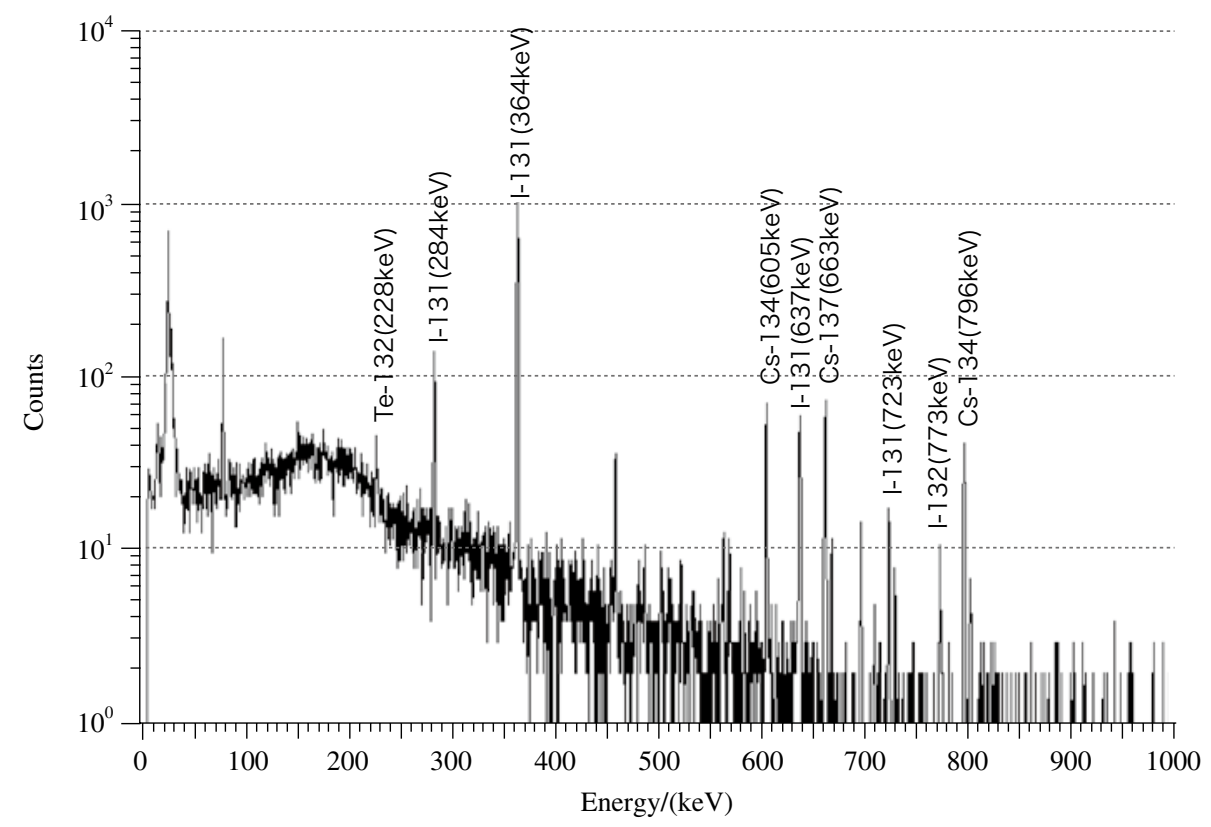

Fig. $1 \gamma$-ray spectrum of the contaminated soil determined on May 15, 2011.

nuclides was $12-26$ for ${ }^{131} \mathrm{I} /{ }^{137} \mathrm{Cs}$ and $1-1.6$ for ${ }^{134} \mathrm{Cs} /{ }^{137} \mathrm{Cs}$, rainwater is estimated to contain less than 30 times the amount of ${ }^{131} \mathrm{I}$ as that of ${ }^{137} \mathrm{Cs}$, and less than twice the amount of ${ }^{134} \mathrm{Cs}$ as that of ${ }^{137} \mathrm{Cs}$.

\section{Effectiveness of removing 1311 from rainwater using various materials}

(Method)

The removal rates $\left({ }^{131} \mathrm{I}+{ }^{134} \mathrm{Cs}+{ }^{137} \mathrm{Cs}\right)$ in Tables 4 and 5 were calculated using the net count rates of a $\gamma$-counter. Since the $\gamma$-counter cannot distinguish between the radioactivity of radioactive iodine and cesium, the obtained values are the removal rates for both nuclides. A negative removal rate in Table 4 indicates that the count rate after filtration was larger than that before filtration. A removal rate exceeding $100 \%$ indicates that the count rate after filtration was smaller than that before filtration.

The removal rates of ${ }^{131} \mathrm{I}$ in Table 6 were calculated from the concentrations of radioactive ${ }^{131} \mathrm{I}$ measured by a Ge semiconductor detector.

(Results)

1) In the filtration, the results of which are given in Table 4, the removal rate after each of the five filtration steps was different for the filter with a $1.2 \mu \mathrm{m}$ pore size. After five steps of ultrafiltration using a $2.6 \mathrm{~nm}$ pore size, all the ${ }^{131} \mathrm{I},{ }^{134} \mathrm{Cs}$, and ${ }^{137} \mathrm{Cs}$ was completely removed. Some filters resulted in an increase in the radioactivity concentration of the sample water after filtration. Although the removal rate of $132 \%$ after the fifth step for the pore size of $2.6 \mathrm{~nm}$ was higher than $100 \%$, since the count rate of the filtered water was small after the fourth step of filtration, the figure of $132 \%$ may contain a large error.

2) The removal rate in the case of using ion exchange resin (a mixed resin containing cations and anions) for ${ }^{131} \mathrm{I},{ }^{134} \mathrm{Cs}$, and ${ }^{137} \mathrm{Cs}$ was $73 \%$, as given in Table 5 .

Table 4 Rates of total ${ }^{131} \mathrm{I},{ }^{134} \mathrm{Cs}$, and ${ }^{137} \mathrm{Cs}$ removal using filtration and ultrafiltration.

\begin{tabular}{|c|c|c|c|c|c|}
\hline \multirow{2}{*}{ Method } & \multirow{2}{*}{ Filter Material (Pore Size) } & \multirow{2}{*}{ Location of Experiment } & \multicolumn{2}{|r|}{ Sample } & \multirow{2}{*}{$\mathrm{R}(\%)$ of $\left({ }^{131} \mathrm{I}+{ }^{134} \mathrm{Cs}+{ }^{137} \mathrm{Cs}\right)$} \\
\hline & & & Type of Water & Location of Collection & \\
\hline \multirow{3}{*}{ Filtration } & Membrane Filter $(1.2 \mu \mathrm{m})$ & \multirow{5}{*}{ TKS } & \multirow{5}{*}{ Rainwater } & \multirow{5}{*}{ Tokyo Metropolita Area } & 21 \\
\hline & Membrane Filter $(0.45 \mu \mathrm{m})$ & & & & -27 \\
\hline & Membrane Filter $(0.2 \mu \mathrm{m})$ & & & & 5 \\
\hline \multirow{2}{*}{ Ultrafiltration } & YM-100 Filter (10 nm) & & & & -11 \\
\hline & YM-1 Filter (2.6 nm) & & & & 132 \\
\hline
\end{tabular}


Table 5 Rates of total ${ }^{131} \mathrm{I},{ }^{134} \mathrm{Cs}$, and ${ }^{137} \mathrm{Cs}$ removal using ion exchange resin, silver ions, and silver Nps.

\begin{tabular}{|c|c|c|c|c|c|}
\hline \multirow{2}{*}{ Method } & \multirow{2}{*}{ Material } & \multirow{2}{*}{ Location of Experiment } & \multicolumn{2}{|r|}{ Sample } & \multirow{2}{*}{$\mathrm{R}(\%)$ of $\left({ }^{131} \mathrm{I}+{ }^{134} \mathrm{Cs}+{ }^{137} \mathrm{Cs}\right)$} \\
\hline & & & Type of Water & Location of Collection & \\
\hline Ion Exchange Resin & Mixed Resin & \multirow{3}{*}{ TKS } & \multirow{3}{*}{ Rainwater } & \multirow{3}{*}{ Tokyo Metropolita Area } & 73 \\
\hline Silver lons & $\mathrm{Ag}^{+} / \mathrm{Zr}_{2}\left(\mathrm{PO}_{4}\right)_{3}$ & & & & 59 \\
\hline Silver Nanoparticles (NPs) & Ag NPs/Clay & & & & 18 \\
\hline
\end{tabular}

Table 6 Rates of ${ }^{131}$ I removal from rainwater using various materials.

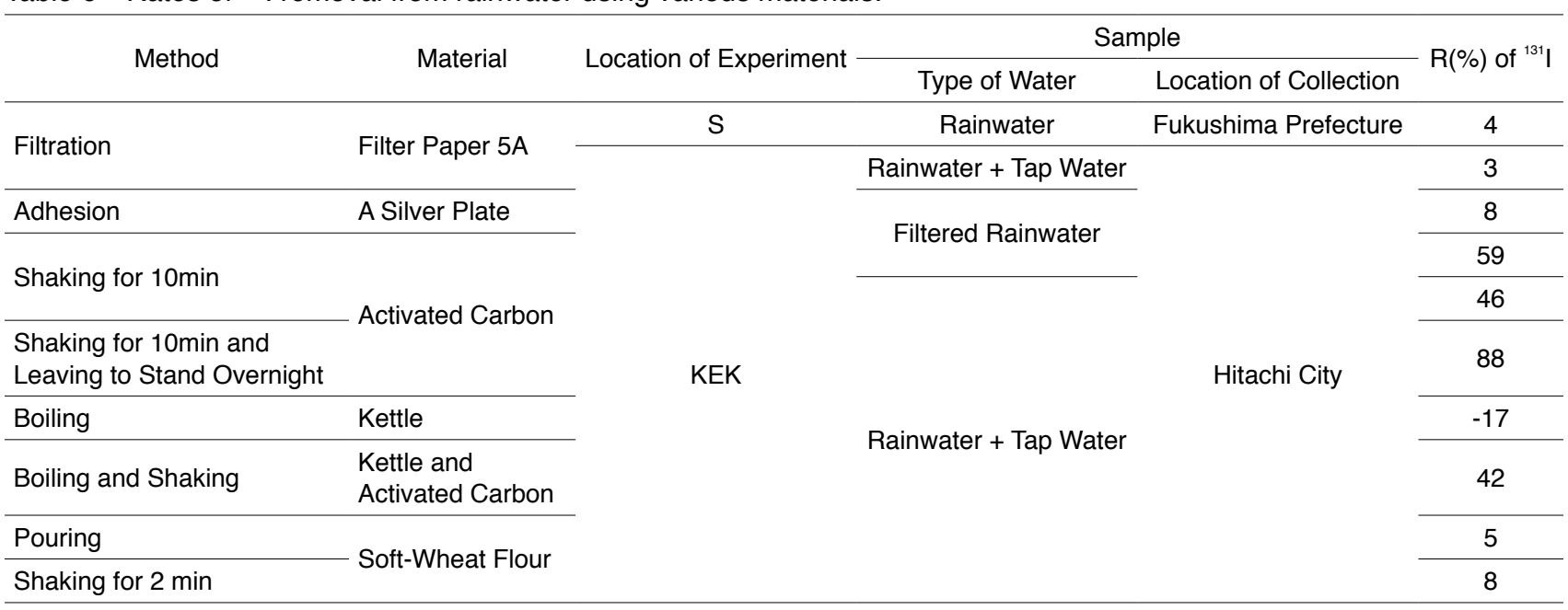

3) The removal rate for $\mathrm{Ag}$ ions fixed with zirconium phosphate for ${ }^{131} \mathrm{I},{ }^{134} \mathrm{Cs}$, and ${ }^{137} \mathrm{Cs}$ was $59 \%$.

4) The removal rate for $\mathrm{Ag}$ nanoparticles fixed with montmorillonite clay for ${ }^{131} \mathrm{I},{ }^{134} \mathrm{Cs}$, and ${ }^{137} \mathrm{Cs}$ was $18.2 \%$.

5) The removal rate for $5 \mathrm{~A}$ filter paper was $3.5 \%$ for ${ }^{131} \mathrm{I}$ and $26.3 \%$ for ${ }^{137} \mathrm{Cs}$ (data not shown).

6) The removal rate for ${ }^{131} \mathrm{I}$ by adhesion to a $\mathrm{Ag}$ plate was $8 \%$, as given in Table 6 .

7) The removal rate for ${ }^{131} \mathrm{I}$ obtained using activated carbon increased from $46 \%$ to $88 \%$ by allowing the contaminated sample to stand for one night before filtering.

8) The concentration radioactive ${ }^{131} \mathrm{I}$ was increased by $17 \%$ when the sample was boiled in an electric kettle, indicating that the radioactive iodine was concentrated.

9) The removal rate for ${ }^{131} \mathrm{I}$ using soft-wheat flour was 5 to $8 \%$.

(Consideration)

1) In the removal experiments whose results are given Tables 4 and 5 , the total removal rates of ${ }^{131} \mathrm{I},{ }^{134} \mathrm{Cs}$, and ${ }^{137} \mathrm{Cs}$ were calculated using the net count rates obtained from the total g-measurement indicated by the g-counter. Nuclide analysis using a Ge detector was then performed to reconfirm the removal rate. In the filtration, although the removal rate decreased after each of the five filtrations, a removal rate of more than $100 \%$ was obtained in the case of ultrafiltration with a 2.6 $\mathrm{nm}$ pore size because the radioactivity concentration of the sample water was low (Table 4). An experiment using more highly radioactive water should be carried out in future.

2) The removal rate was $8 \%$ for $\mathrm{Ag}$ plate adhesion, $18.2 \%$ in the case of using Ag NPs, and 59\% for Ag ions. This result indicates that the removal rate increased as a result of the high reactivity of silver.

3) The negative removal rate in the case of boiling in an electric kettle indicates that ${ }^{131} \mathrm{I}$ was concentrated by boiling the sample water.

3. Effectiveness of removing ${ }^{131} \mathrm{I},{ }^{134} \mathrm{Cs}$, and ${ }^{137} \mathrm{Cs}$ from rainwater using commercial pot-type water purifiers

The removal rates of ${ }^{131} \mathrm{I},{ }^{134} \mathrm{Cs}$, and ${ }^{137} \mathrm{Cs}$ in rainwater using commercial water purifiers were determined considering the fact that nonradioactive $\mathrm{I}_{3}{ }^{-}$was removed with high efficiency from a water sample using a commercial water purifier with high efficiency (section [1]1). 
Water analysis group

Table 7 Initial rates of ${ }^{131} \mathrm{I}$ and ${ }^{137} \mathrm{Cs}$ removal from rainwater using various pot-type water purifiers.

\begin{tabular}{|c|c|c|c|c|c|c|}
\hline \multirow{2}{*}{$\begin{array}{l}\text { Pot-type Water } \\
\text { Purifer }\end{array}$} & \multirow{2}{*}{ Filter Materials } & \multirow{2}{*}{$\begin{array}{l}\text { Location of } \\
\text { Experiment }\end{array}$} & \multicolumn{2}{|r|}{ Sample } & \multirow{2}{*}{$R(\%)$ of ${ }^{131} I$} & \multirow{2}{*}{$\mathrm{R}(\%)$ of ${ }^{137} \mathrm{Cs}$} \\
\hline & & & Type of Water & Location of Collection & & \\
\hline$A$ & Activated Carbon & $\mathrm{T}$ & Rainwater & Tokyo Metropolitan Area & 78 & - \\
\hline \multirow{3}{*}{ B } & \multirow{3}{*}{$\begin{array}{l}\text { Activated Carbon + Ion } \\
\text { Exchanger }\end{array}$} & \multirow{2}{*}{ KEK } & \multirow{2}{*}{$\begin{array}{c}\text { Rainwater + Tap } \\
\text { Water }\end{array}$} & \multirow{2}{*}{ Hitachi City } & 70 & \multirow{2}{*}{-} \\
\hline & & & & & 81 & \\
\hline & & $\mathrm{T}$ & Rainwater & Fukushima Prefecture & 98 & 84 \\
\hline \multirow{2}{*}{$\mathrm{C}$} & \multirow{2}{*}{$\begin{array}{l}\text { Activated Carbon + Ion } \\
\text { Exchanger Resin }\end{array}$} & \multirow{2}{*}{ TKS } & \multirow{2}{*}{ Rainwater } & Tokyo Metropolitan Area & - & - \\
\hline & & & & Fukushima Prefecture* & 81 & - \\
\hline \multirow[t]{2}{*}{$\mathrm{D}$} & \multirow{2}{*}{$\begin{array}{l}\text { Hollow Fiber Filter, } \\
\text { Ceramic + Activated } \\
\text { Carbon }\end{array}$} & KEK & $\begin{array}{c}\text { Rainwater + Tap } \\
\text { Water }\end{array}$ & Hitachi City & 71 & - \\
\hline & & $S$ & Rainwater & Fukushima Prefecture & 97 & 93 \\
\hline $\mathrm{E}$ & $\begin{array}{l}\text { Activated Carbon }+ \\
\text { Ceramic }+ \text { Hollow Fiber } \\
\text { Filter, Calcium Sulphate }\end{array}$ & $\mathrm{T}$ & Rainwater & Fukushima Prefecture & 94 & 90 \\
\hline
\end{tabular}

${ }^{*}$ Average of two removal rates

A: Laica Capri (Italy), B: Toray Torayvino PT302 (Japan), C: Brita Navelia (Germany), D: Mitsubishi Rayon Cleansui CP002 (Japan), E: Panasonic TK-CP11 (Japan)

\subsection{Effectiveness of removing ${ }^{131}$ I from rainwater using commercial pot-type water purifiers}

(Method)

There are three main types of commercial water purifier: pottype, faucet-mounted-type, and countertop-type. In this study we only used general-purpose pot-type water purifiers, since we did not have equipment to pressurize the rainwater to enable the use of faucet-mounted-type and countertop-type purifiers, which require direct connection to a water pipe. We used pot-type water purifiers with activated carbon as the basic filter material, because the removal rate of ${ }^{131} \mathrm{I}$ from rainwater was $88 \%$ using activated carbon (Table 6) and that of nonradioactive $I_{2}$ and I was $98 \%$ using activated carbon (Table 1). In addition to activated carbon as the basic filter material, ion exchange resin, a hollow fiber filter, or a ceramic was added to the water purifiers as a secondary filter material, their effect on the removal of radioactive iodine and cesium was investigated. Five different water purifiers with the filter materials shown in Table 7 were used, and the experiments on the removal of ${ }^{131} \mathrm{I}$ from rainwater were carried out at the four universities and one organization.

(Results)

1) The removal rates of ${ }^{131} I$ for commercial water purifiers (A- E) were 70 to $98 \%$.

2) The removal rate for ${ }^{131} I$ varied with the sampling location.
(Consideration)

1) The removal rate of $98 \%$ for nonradioactive iodine in the model experiment (Table 1) was the same as the maximum removal rate for ${ }^{131} \mathrm{I}$ in Table 7 . This indicates that radioactive iodine such as $\mathrm{I}_{2}$ and I can be completely removed by using activated carbon and ion exchange resin. The removal rate for contaminated rainwater was lower than that obtained in the model experiment and depended on the location of collection. This indicates that the components in the rainwater varied with the location of collection.

2) The maximum removal rate for ${ }^{131} \mathrm{I}$ of $98 \%$ using the commercial pot-type water purifiers indicates that the rainwater contained substances (remaining components) that were not removed by activated carbon and ion exchange resin.

3) The ratio of the components removed by the water purifiers to the remaining components may depend on the chemical form of ${ }^{131} \mathrm{I}$ and the size of the adsorbed substances, which, in turn, depend on the date of rainfall and the distance from the generation source.

4) The removal rate for the pot-type water purifiers obtained in this experiment cannot be applied to faucet-mounted- or countertop-type purifiers but can be used as a reference to estimate the removal rate. It is necessary to determine the removal rate of pressurized-type water purifiers.

5) Although a charcoal filter used for the filtration of contaminated air captures ${ }^{131} \mathrm{I}$ in the air, the captured ${ }^{131} \mathrm{I}$ is known to escape from the filter over time. The rate of loss of ${ }^{131} \mathrm{I}$ has 
Table 8 Removal rates for consecutive purifications using various commercial water purifiers.

(1) Removal rates of ${ }^{131} \mathrm{l}$.

\begin{tabular}{|c|c|c|c|c|c|c|c|c|}
\hline $\begin{array}{c}\text { Pot-type Water } \\
\text { Purifer }\end{array}$ & $\begin{array}{l}\text { Location of } \\
\text { Experiment }\end{array}$ & Type of Water & $\begin{array}{l}\text { Location of } \\
\text { Collection }\end{array}$ & $R(\%)-1$ of ${ }^{131}$ I & $R(\%)-2$ of ${ }^{131} \mathrm{I}$ & $\mathrm{R}(\%)-3$ of ${ }^{131} \mathrm{I}$ & $R(\%)-4$ of ${ }^{131} I$ & $R(\%)-5$ of ${ }^{131}$ I \\
\hline \multirow{2}{*}{$\begin{array}{l}\text { Toray Torayvino } \\
\text { PT302 }\end{array}$} & KEK & $\begin{array}{l}\text { Rainwater + Tap } \\
\text { Water }\end{array}$ & Hitachi City & 70 & 75 & 78 & 81 & 79 \\
\hline & $\mathrm{T}$ & Rainwater & $\begin{array}{l}\text { Fukushima } \\
\text { Prefecture }\end{array}$ & 98 & 99 & 98 & 98 & 99 \\
\hline Brita Navelia & TKS & Rainwater & $\begin{array}{l}\text { Fukushima } \\
\text { Prefecture }^{*}\end{array}$ & 81 & 90 & 91.5 & 93 & 93.5 \\
\hline $\begin{array}{l}\text { Mitsubishi Rayon } \\
\text { Cleansui CP002 }\end{array}$ & $S$ & Rainwater & $\begin{array}{l}\text { Fukushima } \\
\text { Prefecture }\end{array}$ & 97 & 99 & 99 & 99 & 99 \\
\hline $\begin{array}{l}\text { Panasonic } \\
\text { TK-CP11 }\end{array}$ & $\mathrm{T}$ & Rainwater & $\begin{array}{l}\text { Fukushima } \\
\text { Prefecture }\end{array}$ & 94 & 98 & 99 & 98 & 98 \\
\hline
\end{tabular}

${ }^{*}$ Average of two removal rates

(2) Removal rates of ${ }^{137} \mathrm{Cs}$.

\begin{tabular}{|c|c|c|c|c|c|c|c|c|}
\hline $\begin{array}{c}\text { Pot-type Water } \\
\text { Purifer }\end{array}$ & $\begin{array}{l}\text { Location of } \\
\text { Experiment }\end{array}$ & Type of Water & $\begin{array}{l}\text { Location of } \\
\text { Collection }\end{array}$ & $\begin{array}{l}\mathrm{R}(\%)-1 \text { of } \\
{ }^{137} \mathrm{Cs}\end{array}$ & $\begin{array}{l}\mathrm{R}(\%)-2 \text { of } \\
{ }^{137} \mathrm{Cs}\end{array}$ & $\begin{array}{l}\mathrm{R}(\%)-3 \text { of } \\
{ }^{137} \mathrm{Cs}\end{array}$ & $\begin{array}{l}\mathrm{R}(\%)-4 \text { of } \\
{ }^{137} \mathrm{Cs}\end{array}$ & $\begin{array}{l}\mathrm{R}(\%)-5 \text { of } \\
{ }^{137} \mathrm{Cs}\end{array}$ \\
\hline $\begin{array}{l}\text { Toray Torayvino } \\
\text { PT302 }\end{array}$ & $\mathrm{T}$ & \multirow{3}{*}{ Rainwater } & \multirow{3}{*}{$\begin{array}{l}\text { Fukushima } \\
\text { Prefecture }\end{array}$} & 84 & 97 & 96 & 96 & 94 \\
\hline $\begin{array}{l}\text { Mitsubishi Rayon } \\
\text { Cleansui CP002 }\end{array}$ & $S$ & & & 93 & ND & ND & ND & ND \\
\hline $\begin{array}{l}\text { Panasonic } \\
\text { TK-CP11 }\end{array}$ & $\mathrm{T}$ & & & 94 & 98 & 98 & 98 & 98 \\
\hline
\end{tabular}

(3) Removal rates of ${ }^{134} \mathrm{Cs}$.

\begin{tabular}{|c|c|c|c|c|c|c|c|c|}
\hline $\begin{array}{c}\text { Pot-type Water } \\
\text { Purifer }\end{array}$ & $\begin{array}{l}\text { Location of } \\
\text { Experiment }\end{array}$ & Type of Water & $\begin{array}{l}\text { Location of } \\
\text { Collection }\end{array}$ & $\begin{array}{l}\mathrm{R}(\%)-1 \text { of } \\
{ }^{134} \mathrm{Cs}\end{array}$ & $\begin{array}{l}\mathrm{R}(\%)-2 \text { of } \\
{ }^{134} \mathrm{Cs}\end{array}$ & $\begin{array}{l}\mathrm{R}(\%)-3 \text { of } \\
{ }^{134} \mathrm{Cs}\end{array}$ & $\begin{array}{l}\mathrm{R}(\%)-4 \text { of } \\
{ }^{134} \mathrm{Cs}\end{array}$ & $\begin{array}{l}R(\%)-5 \text { of } \\
{ }^{134} \mathrm{Cs}\end{array}$ \\
\hline $\begin{array}{l}\text { Toray Torayvino } \\
\text { PT302 }\end{array}$ & $\mathrm{T}$ & \multirow{2}{*}{ Rainwater } & \multirow{2}{*}{$\begin{array}{l}\text { Fukushima } \\
\text { Prefecture }\end{array}$} & 78 & 95 & 95 & 95 & 92 \\
\hline $\begin{array}{l}\text { Panasonic } \\
\text { TK-CP11 }\end{array}$ & $\mathrm{T}$ & & & 88 & 98 & 99 & 97 & 96 \\
\hline
\end{tabular}

been reported to be affected by the quantity and rate of the air flow. The capture of ${ }^{131} \mathrm{I}$ by activated carbon in water and its subsequent escape are under investigation. If the captured ${ }^{131}$ I escapes from the activated carbon, it is predicted that the removal rate of faucet-mounted-type and countertoptype water purifiers will be lower than that of pot-type water purifiers.

6) Although the removal rate of ${ }^{131}$ I by pot-type water purifiers is expected to decrease with increasing flow rate of water and the accumulation of radioactivity, no information was obtained about the most efficient flow rate of water or the cumulative effect of radioactivity for pot-type water purifiers.
3.2. Effectiveness of removing ${ }^{131} \mathrm{I},{ }^{134} \mathrm{Cs}$, and ${ }^{137} \mathrm{Cs}$ by consecutive purifications using various commercial water purifiers

(Method)

The removal rates of ${ }^{131} \mathrm{I},{ }^{134} \mathrm{Cs}$, and ${ }^{137} \mathrm{Cs}$ for commercial water purifiers B-E were obtained for consecutive purifications after the experiment on rainwater was carried out.

(Results)

1) As shown in Table 8(1), the removal rate of ${ }^{131} \mathrm{I}$ was increased by consecutive purifications for all water purifiers. The removal rate of ${ }^{131} \mathrm{I}$ after the fifth purification was $3 \%$ (S) for only filtration using filter paper, whereas it was $99 \%$ for purifier D, $99 \%$ for B, $98 \%$ for E, and 92 to $95 \%$ for C.

2) Although solvent extraction of the remaining ${ }^{131} \mathrm{I}$ component using carbon tetrachloride and diethyl ether was attempted 
Table 9 Rates of removal of ${ }^{131} \mathrm{I}$ from water purifier by adding $\mathrm{Na}_{2} \mathrm{~S}_{2} \mathrm{O}_{4}$ and rates of ${ }^{131} \mathrm{I}_{2}$ adsorption onto silica gel.

\begin{tabular}{|c|c|c|c|c|c|}
\hline Method & Treatment & Sample & Location of Collection & $R(\%)$ of ${ }^{131} \mid$ & $\begin{array}{l}\text { Rate (\%) of } \\
\text { Adsorption }\end{array}$ \\
\hline \multirow{4}{*}{$\begin{array}{l}\text { Purification } \\
\text { with Brita } \\
\text { Novelia }\end{array}$} & \multirow{2}{*}{ Addition of $10 \mathrm{~g}$ of $\mathrm{Na}_{2} \mathrm{~S}_{2} \mathrm{O}_{4}$} & 7-Times Purified rainwater & \multirow{4}{*}{ Fukushima Prefecture } & -592 & - \\
\hline & & 6-Times Purified rainwater & & -374 & - \\
\hline & Mix with Silica Gel & \multirow{2}{*}{$\begin{array}{l}\text { Filtered 6-Times Purified Rainwater } \\
\text { Mixed with } 10 \mathrm{~g} \text { of } \mathrm{Na}_{2} \mathrm{~S}_{2} \mathrm{O}_{4}\end{array}$} & & -2 & 17 \\
\hline & Mix with $200 \mathrm{~g}$ of Silica Gel & & & -24 & 19 \\
\hline
\end{tabular}

Table 10 Concentrations of radioactive components after ultrafiltration.

\begin{tabular}{|c|c|c|c|c|c|}
\hline \multirow{2}{*}{ Method } & \multicolumn{2}{|r|}{ Sample } & \multicolumn{2}{|c|}{ Net Count Rate/cpm } & \multirow{2}{*}{$\begin{array}{c}\text { Ratio of Count Rate } \\
\text { Concentrated Solution/Filtrate }\end{array}$} \\
\hline & Type of Water & Location of Collection & Concentrated Solution & Filtrate & \\
\hline \multirow{2}{*}{$\begin{array}{l}\text { Concentration using Ultrafil- } \\
\text { tration with YM-1 Filter)(1) }\end{array}$} & Rainwater & \multirow{2}{*}{ Tokyo Metropolitan Area } & 323 & 55 & 5.9 \\
\hline & $M(1)+$ Rainwater & & 220 & 156 & 1.4 \\
\hline
\end{tabular}

after the fifth purification with water purifier D, most of the

${ }^{131}$ I remained in the water phase and only a small quantity of

${ }^{131} \mathrm{I}$ in the organic phase was detected.

3) As shown in Table 8(2), the removal rate of ${ }^{137} \mathrm{Cs}$ was $26 \%$

(S) for only filtration using filter paper, whereas it was $100 \%$ for D after the second purification, $94 \%$ for B after the fifth purification, and $98 \%$ for $\mathrm{E}$ after the fifth purification. These results cannot be applied to faucet-mounted- or countertoptype purifiers but can be used for reference.

4) As shown in Table 8(3), the removal rate of ${ }^{134} \mathrm{Cs}$ was $92 \%$ for B after the fifth purification and $96 \%$ for $\mathrm{E}$ after the fifth purification.

(Consideration)

1) As shown in Tables 8 (1) and (2), 90-99\% of ${ }^{131} \mathrm{I}$ and 94$100 \%$ of ${ }^{137} \mathrm{Cs}$ were removed by consecutive purifications, respectively, although differences in the removal rates were observed among the water purifiers. The results indicate that water purifiers can be easily used to remove ${ }^{131} \mathrm{I}$ and ${ }^{137} \mathrm{Cs}$ at a general home.

2) The remaining components, which contain ${ }^{131} \mathrm{I}$, were concluded to be hydrophilic because they were not extracted by carbon tetrachloride and diethyl ether.

3) ${ }^{137} \mathrm{Cs}$ has two different components, which are easily removed by a $5 \mathrm{~A}$ filter paper and by filtration using a water purifier, respectively.

\section{Estimation of remaining components after con- secutive purifications (TKS)}

(Method)

Since tap water reaches general residential houses after being purified with activated carbon and other materials at water purification plants, the remaining ${ }^{131} \mathrm{I}$ in the purified rainwater may have the same components as tap water. Therefore, it is necessary to find a method for removing the remaining ${ }^{131} \mathrm{I}$. The chemical form of the remaining ${ }^{131} \mathrm{I}$ was investigated by isotope exchange with nonradioactive iodide after the purification of $1 \mathrm{mM} \mathrm{I}_{3}^{-}$aqueous solution, reduction to $\mathrm{I}^{-}$using $\mathrm{Na}_{2} \mathrm{~S}_{2} \mathrm{O}_{8}$, adsorption onto silica gel, fractionation with ultrafiltration, and coagulation with silica NPs.

(Results)

1) As shown in Table 9, the removal rate of ${ }^{131} \mathrm{I}$ was $95.2 \%$, which was almost the same as that $(94.9 \%)$ before purification with $1 \mathrm{mM}$ nonradioactive $\mathrm{I}_{3}^{-}$. Although $\mathrm{Na}_{2} \mathrm{~S}_{2} \mathrm{O}_{8}$ was added to the solution containing the remaining ${ }^{131} \mathrm{I}$ and the mixture was purified, the removal rate did not increase. These results suggest that $\mathrm{I}^{-}$and $\mathrm{I}_{2}$ do not exist on the surface of the remaining components.

2) Table 10 suggests that the remaining components are composed of substances of more than $1000 \mathrm{MWCO}$, because ${ }^{131} \mathrm{I}$ solution with approximately 5.9 times higher concentration was obtained by the ultrafiltration (YM-1, MWCO1000) of rainwater.

3) As shown in Table 11, the addition of $\mathrm{I}_{3}^{-}$-treated silica NPs to the concentrated rainwater samples caused the coagulation and precipitation of the radioactive components. The precipitate contained $52 \%{ }^{131} \mathrm{I}, 59 \%{ }^{137} \mathrm{Cs}$, and $75 \%{ }^{134} \mathrm{Cs}$ relative to the amounts before treatment. This indicates that the ${ }^{131}$ I-containing components that adsorbed on the silica NPs were precipitated. It was also found that an ${ }^{131}$ I-containing component was adsorbed on the silica gel. 
Table 11 Coagulation of radioactive components using $\mathrm{I}_{3}$-treated silica NPs.

\begin{tabular}{|c|c|c|c|c|c|c|}
\hline Sample & Method & $\begin{array}{l}\text { Ratio of Concentrated } \\
\text { Solution and Filtrate }\end{array}$ & $\begin{array}{l}\text { Net Count } \\
\text { Rate/cpm }\end{array}$ & Integral of & Area & spectra \\
\hline $\begin{array}{l}\text { Concentrated Solution } \\
\text { (Supernatant + Precipitate) }\end{array}$ & \multirow{4}{*}{$\begin{array}{l}\text { Ultrafiltration of Rainwater } \\
\text { Mixed with Silica NPs }(7 \mathrm{~nm})-\text { I }\end{array}$} & \multirow{4}{*}{8.7} & 832 & 410.5 & 266 & 196 \\
\hline Supernatant $(3 \mathrm{ml})$ & & & - & 269 & 48 & 33 \\
\hline Precipitate $(0.5 \mathrm{ml})$ & & & - & 211.5 & 200 & 115 \\
\hline Filtrate & & & 96 & - & - & - \\
\hline
\end{tabular}

(Consideration)

The remaining components were not only simple radioactive iodine but also radioactive iodide bound or adsorbed onto substances of more than $1000 \mathrm{MWCO}$, indicating the possibility of their adsorption onto silica.

\section{Summary}

1. The removal rate of $98 \%$ for nonradioactive iodide in a model experiment suggested that radioactive iodide can be removed using a commercial water purifier with activated carbon.

2 . In the removal experiments using ${ }^{125} \mathrm{I}$ model solution, relatively high removal rates of $70 \%$ for $\beta$-CDP and $85 \%$ for pretreated activated carbon were obtained, suggesting that, for the removal of radioactive ${ }^{131} \mathrm{I}$, the use of activated carbon is as effective as that for removing nonradioactive iodide.

3. Although in the case of rainwater, ${ }^{131} \mathrm{I}$ as a chemical form of $\mathrm{I}_{2}$ and I can be efficiently removed using a commercial pot-type water purifier with activated carbon and ion exchange resin, even after consecutive purifications there are unremoved substances containing ${ }^{131} \mathrm{I}$ (remaining components).

4. The remaining components are suggested to be hydrophilic because they were not extracted by diethyl ether and carbon tetrachloride.

5. Since the size of the chemical form of ${ }^{131} \mathrm{I}$ and that of the adsorbing substance are different, the ratios of the removed components to the remaining components in the contaminated rainwater are different for different water purifiers.

6. The possibility that part of the residual components can be adsorbed onto silica NPs was demonstrated.

7. There are two forms of ${ }^{137} \mathrm{Cs}$, one that is insoluble in rainwater and can be easily removed with $5 \mathrm{~A}$ filter paper, and one that can be removed using a water purifier.

8. ${ }^{131}$ I was concentrated when a contaminated sample was boiled in a kettle.

9. Although we predict that faucet-mounted-type and countertoptype purifiers will have the same performance as pot-type purifiers, it is necessary to experimentally determine the removal rate for such built-in-type water purifiers.

10. It is also necessary to determine the effects of an increasing rate of water flow and the accumulation of radioactivity on the efficiency of pot-type water purifiers.

\section{Water analysis group}

Leader:

Hirokazu Miyoshi (Radioisotope Research Center, The University of Tokushima)

Deputy Leader:

Shogo Higaki (Radioisotope Center, The University of Tokyo)

Members

Kazuyoshi Masumoto (Radiation Science Center, High Energy Accelerator Research Organization)

Norio Nogawa (Radioisotope Center, The University of Tokyo)

Masahiro Hirota (Department of Nuclear Engineering and Management, The University of Tokyo)

Makoto Yanaga (Radioscience Research Laboratory, Faculty of Science, Shizuoka University)

Takuya Saze (Radioisotope Research Center, The University of Tokushima)

Keisuke Sueki (Radioisotope Center, University of Tsukuba)

\section{Research Collaborators}

Hiroshi Matsumura, Akihiro Toyota, Kazutomo Takahashi (Radiation Science Center, High Energy Accelerator Research Organization) 